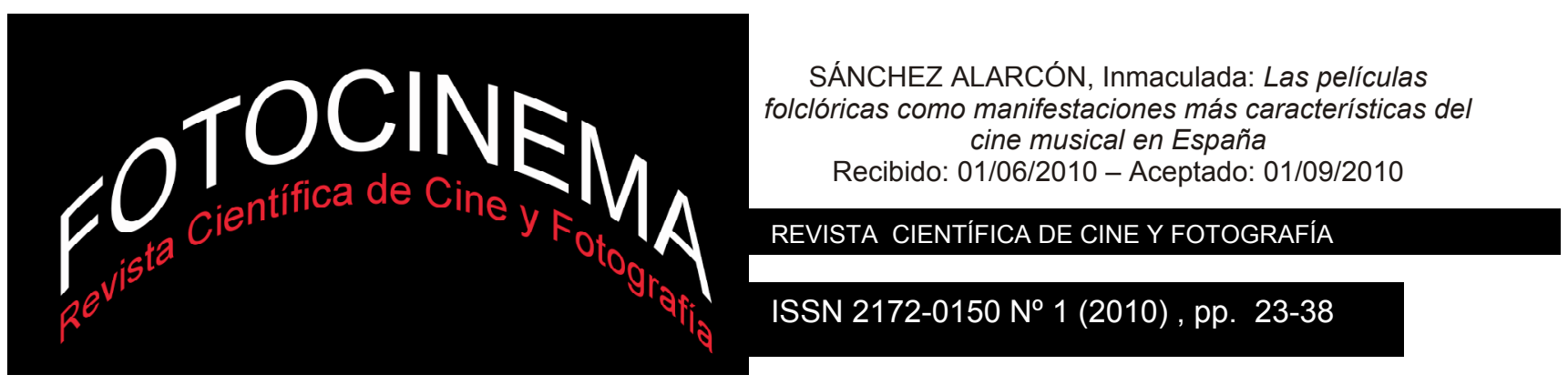

\title{
LAS PELÍCULAS FOLCLÓRICAS COMO MANIFESTACIONES MÁS CARACTERÍSTICAS DEL CINE MUSICAL EN ESPAÑA
}

\section{Inmaculada Sánchez Alarcón}

Universidad de Málaga

\section{Resumen:}

El cine musical producido en España incluye manifestaciones de vanguardia, como las películas de Carlos Saura. Sin embargo, los ejemplos más importantes de este género son los que tienen una finalidad comercial. El cine folclórico de temática andaluza es la manifestación más específica del musical español. En este artículo se establece primero un panorama general de la evolución experimentada por el género cinematográfico musical en España. Luego se analizan los rasgos narrativos más sobresalientes del cine folclórico durante su época de esplendor, entre mediados de los años treinta y principios de los sesenta. Por último, se trata de Pena, penita, pena (Miguel Morayta, 1953), protagonizada por una de las grandes estrellas del musical folclórico, Lola Flores, porque se trata de una coproducción concebida también para el mercado latinoamericano.

\begin{abstract}
:
The film musical produced in Spain includes avant-garde examples, as Carlos Saura's films. However, the most important titles of this genre are those with a commercial purpose. The folk cinema located in Andalusia is the most specific type of Spanish film musical. First, this text provides a general approach to the evolution of the film musical in Spain. Then it analyzes the most important narrative features of the folk films during its best period, between the mid-thirties and early sixties. Finally, the point at the issue is Pena, penita, pena (Miguel Morayta, 1953), starred one of the greatest stars of folk musicals, Lola Flores, because it is a folk film musical and it is also cofunded for the Latin American market.
\end{abstract}

\section{Palabras clave:}

Cine musical español, musical folclórico, Andalucía, Lola Flores.

\section{Key words:}

Spanish musical cinema, folk musical, Andalusia, Lola Flores 
Son los duros años cuarenta y España sufre las consecuencias de la Guerra Civil. Pepita y Balbina están sentadas en un cine contemplando la proyección de un musical. Estrellita Castro, la gran estrella española, lujosamente ataviada, canta una canción. Las dos mujeres miran fascinadas a la pantalla y comparten la esperanza de que Pepita también pueda convertirse en una estrella de la copla y salir de la miseria...

Pepita y Balbina son dos personajes interpretados por Amparo Baró y Ángela Molina en Las cosas del querer, una película dirigida por Jaime Chavarri en 1989. La secuencia descrita ilustra cómo los musicales del franquismo, sus protagonistas y sus canciones, dejaron una gran huella en la memoria colectiva de los españoles.

Tanto en el franquismo como después, en España se han producido muchas películas en las que sobre todo las canciones ocupan un lugar central. Este tipo de películas, de todas maneras, adquieren ya una clara relevancia a partir del importantísimo éxito de público obtenido por La hermana San Sulplicio (Florián Rey, 1934), durante el periodo republicano. Pero aquí también se siguen produciendo títulos ajustados a este género a partir de la transición democrática. A partir de mediados de los 8o, lo mismo que en otros países, los musicales sólo son una notable excepción en la producción cinematográfica española. Se ha cuestionado si existe un cine musical propiamente dicho o si en este país sólo se producen películas de género ilustradas con canciones (Fernández Heredero, 1993: 181). La escasez de análisis teóricos específicos ha contribuido a estos planteamientos.

Entre los musicales producidos en España, existen ejemplos de carácter vanguardista, como Embrujo (Carlos Serrano de Osma, 1947), en la que el flamenco aparece con una dimensión surrealista. Pero ha sido sobre todo Carlos Saura quien construye una visión novedosa del género a partir de Bodas de sangre (1981), que recoge el ensayo de la versión coreográfica de la obra de Lorca por parte de la compañía del bailarín Antonio Gades. Desde entonces, Saura ha dirigido bastantes películas musicales. Algunas, como Salomé (2002), responden al mismo esquema de su primera película de este género. Otras, sin embargo, como Sevillanas (1992), que recoge diferentes números que ilustran 
distintas modalidades del baile popular del mismo nombre, o Flamenco (1995), un conjunto de interpretaciones de este estilo musical, constituyen visiones personales sobre distintos tipos de música o de baile. El uso de la luz y del espacio en la puesta en escena y el manejo de la cámara singularizan estas obras de Saura. Su colaboración con Vittorio Storaro, director de fotografía in Flamenco y Tango (1998), o José Luis López Linares, que ejerce esta misma función en Salomé, Iberia (2005) o Fados (2007), por ejemplo, es un elemento clave para la importancia que adquieren estos elementos de la puesta en escena en las películas de Carlos Saura.

Sin embargo, el musical cinematográfico español se ha orientado, sobre todo, en función de los resultados comerciales. Un ejemplo claro es el del llamado "cine de cuplé" (Monterde, 1995: 271). En 1957, Sara Montiel, que entonces trabajaba en Hollywod, protagonizó El último cuplé. Dirigida por Juan de Orduña, la película se centra en una cantante de cuplés, canciones de moda en los espectáculos de variedades franceses y que se popularizan también en España sobre todo desde 1900. El enorme éxito obtenido inauguró un conjunto de historias melodramáticas que se situaban en el mundo del espectáculo a finales del XIX o principios del XX, y que incluían cuplés y otras canciones populares. La misma Sara Montiel protagoniza varios títulos más ajustados a esta fórmula, como La violetera (Luis César Amadori, 1958). Imitadoras como Marujita Díaz encabezarían los repartos de películas similares sin tanto éxito artístico ni de público. La Coquito (Pedro Masó, 1977) es un musical más tardío que desarrolla un esquema similar, pero el "cine de cuplé” se agotó en los 60: a pesar del epígono realizado más de una década después, las limitaciones de las pautas estilísticas y narrativas de los títulos ajustados a este modelo eran ya entonces más qué evidentes.

Los musicales españoles también siguen líneas coincidentes con el musical norteamericano, aunque ajustadas al público nacional. Por ejemplo, una de las fórmulas más rentables en la España franquista mezcla el musical folclórico andaluz y el cine con niño, sobre todo con Joselito, cuya primera película es $E l$ pequeño ruiseñor (Antonio del Amo, 1956), y Marisol, que protagoniza varios títulos con planteamientos más modernos a partir de Un rayo de luz (Luis Lucia, 1960). Rubia y de ojos claros, la pequeña cantante malagueña disfruta de 
un enorme éxito con las producciones que protagoniza en una España que sale de la autarquía franquista y que la ve como un símbolo de la tan ansiada modernidad. Muy cercano a un estilo pop, este tipo de musical que se origina con Marisol seguirá en los 60 con figuras adolescentes como Rocío Dúrcal. En décadas posteriores, destacan las películas protagonizadas por el grupo "Parchís" a partir de La guerra de los niños (Javier Aguirre, 1980).

Como en el cine británico, el éxito de las películas de Elvis Presley también motiva la realización de películas españolas concebidas como vehículos para las estrellas del pop desde mediados de los años 6o. Al contrario de lo que ocurre en décadas anteriores, cuando los musicales protagonizados por cantantes se conciben para conseguir el éxito en el mercado cinematográfico, en las películas protagonizadas por figuras como Raphael, Julio Iglesias o el Dúo Dinámico o grupos como "Los Bravos", se pretende acentuar el atractivo de los músicos y aumentar las ventas de sus discos.

Estos musicales suelen ajustarse a la fórmula de la comedia romántica con elementos melodramáticos. Los cantantes protagonistas interpretan a personajes que ejercen su misma profesión y que a veces pueden sufrir una crisis vital. Es el caso de Raphael en Al ponerse el sol (Mario Camus, 1967) o Julio Iglesias en Me olvidé de vivir (Orlando Jiménez Leal, 1979). La repetida intervención de compositores como Augusto Algueró, responsable en siete de los títulos de Marisol y en otros de Rocío Dúrcal, y las puestas en escena poco imaginativas uniformizan estos musicales. Pero también hay que destacar películas artísticamente más exigentes, como el título protagonizado por Raphael que se ha citado y cuyo director es uno de los jóvenes formados en la Escuela Oficial de Cine que participa en el denominado "Nuevo Cine Español”.

Además, hay que destacar la singularidad de las dos películas protagonizadas por "Los Brincos", un grupo de pop que consigue entrar en las listas británicas y estadounidenses con Black is Black en 1966. Estas incursiones en el cine son Los chicos con las chicas (Javier Aguirre, 1967) y Dame un poco de amor (José María Forqué, 1968). Ambos títulos recuerdan mucho a A hard day's night (Richard Lester, 1964). Ayudan a ello el humor surrealista, la inclusión de números musicales que no se integran en la narración, claros antecedentes del videoclip, y la estética psicodélica.

Desde los años 6o, que, junto con la década anterior, son la etapa más prolífica 
del género, en España se producen menos musicales. Hay ejemplos poco usuales como A tope (Ramón Fernández, 1984), dónde participan los grupos más destacados de "la movida" iniciada con la democracia. Con el referente de On connaît la chanson (Alain Resnais, 1997), en 2002 Emilio Martínez Lázaro dirige El otro lado de la cama, sobre un grupo de treintañeros sentimentalmente desorientados. A diferencia de la película francesa, dónde los actores interpretan play-backs de las baladas originales, en este ejemplo español son los actores quienes bailan e interpretan canciones españolas famosas en los 80. Los buenos resultados obtenidos en la taquilla dieron lugar a una secuela similar, Los dos lados de la cama (2005).

¿Por qué se frotan las patitas? (Álvaro Bejines, 2006), una de las películas españolas más reciente de este género, puede definirse como una reelaboración postmoderna del musical derivado de la cultura andaluza o musical folclórico. En la película de Begines, los actores interpretan versiones de éxitos musicales recientes en play-back: como en el caso del Aserejé, las canciones que componen su banda sonora se pueden considerar las versiones actualizadas de las populares coplas de las películas de los años 40 y 50. El principal personaje femenino, María (Lola Herrera), es una cantante folclórica andaluza que mantiene una historia de amor en secreto con el suegro de su hijo: esta reelaboración fuera de las convenciones de un tipo de personaje definido tradicionalmente por sus rasgos conservadores es una clara muestra de los planteamientos postmodernos de esta película.

Pero esta reconstrucción irónica de los tópicos relativos al musical folclórico andaluz es una excepción. Después de su gran época de auge, que será analizada en el próximo apartado, siguen produciéndose películas folclóricas ajustadas a los cánones más tradicionales hasta la transición política. Manolo Escobar, la última gran estrella de este tipo de musicales, obtiene grandes éxitos desde sus primeras apariciones en el cine, durante los años 60, hasta Todo es posible en Granada (Rafael Moreno Marchent, 1982), la última película protagonizada por él.

También en los años 80 hay musicales que se ajustan a la fórmula folclórica. El auge de la copla andaluza en la España de los 80 y de los 90 es una causa. Pero sus pautas características también adquieren una clara justificación diegética porque las narraciones están enmarcadas en el periodo de mayor auge de este 
género, la posguerra. Es el caso de Las cosas del querer, antes citada, Las cosas del querer II (Jaime Chávarri, 1995) o La niña de tus ojos (Fernando Trueba, 1998), en las que la memoria del cine folclórico sirve para acercarse al franquismo. Pero la perspectiva crítica que adoptan estas películas contemporáneas las aparta con claridad de la fórmula que caracteriza los musicales folclóricos originales.

Ya con una intencionalidad claramente comercial, también hay intentos de revivir este cine folclórico más clásico a través de dos famosas cantantes, Isabel Pantoja, que protagoniza Yo soy esa (Luis Sanz, 1990) y El día que nací yo (Pedro Olea, 1991), y Rocío Jurado, que interviene en La Lola se va a los puertos (Josefina Molina, 1993). Entre todos estos títulos sólo Yo soy esa se ajusta estrictamente a los cánones clásicos del musical folclórico. Pero más que estas manifestaciones recientes, para definir el musical folclórico español es preciso evaluar los rasgos que adquiere en su época de esplendor.

\section{El cine folclórico y su especificidad en la historia del musical español}

Ya desde los años 20, en España se realizan adaptaciones cinematográficas de fórmulas como las zarzuelas, obras de teatro de rasgos costumbristas en las que las canciones forman parte en la narración. El objetivo de la industria cinematográfica española es un espectador popular que se asiste con regularidad a este tipo de representaciones en los teatros.

Desde entonces son frecuentes las películas musicales en las que se reflejan formas de hablar u otras características significativas de distintos lugares de España, entre los que Andalucía es el más aparecido. En los años 30 se utiliza el término "españolada” para denominar este tipo de producciones. Pero los rasgos de esta fórmula se establecen ya en las obras de artistas extranjeros que llegan a España en el siglo XIX. La pasión y el misterio tradicionalmente identificados con Andalucía fueron los rasgos que más atrajeron a estos viajeros que llegan a nuestro país en este periodo. Después, estos mismos rasgos seguirían utilizándose para vender la imagen de España en el exterior: no hay más que recordar la secuencia del baile flamenco que incluye Bigas Luna en la 
pieza audiovisual que se encarga de dirigir para el pabellón español en la Exposición Universal de Shangai durante este año 2010.

La música andaluza, de hecho, ya tiene una función importante en las obras de los intelectuales extranjeros que llegan a la España de finales del siglo XIX: la bailaora y el cantaor son, junto al torero, el bandolero o Carmen, dos de las figuras en las que se personifica la esencia de lo español, que se identifica con Andalucía.

Desde los inicios del cine español, incluso se componen partituras para añadirlas a historias que, antes de ser llevadas al cine, no incluyen canciones ni bailes. Este es el caso de Morena Clara (Florián Rey, 1936), que obtiene un enorme éxito. En los musicales que se realizan en España entre los años 30 y los años 50, es frecuente, además, que los protagonistas interpreten las mismas coplas, mezclas del cuplé y de la música andaluza, con las que ya han triunfado como cantantes. Las composiciones incluidas en las películas también se interpretan luego en espectáculos teatrales.

Juan Quintero, Rafael de León y Manuel Quiroga están entre los compositores que más contribuyen al éxito de los musicales folclóricos. Juntos y por separado, los tres aparecen en los títulos de crédito de veinticinco musicales realizados entre 1940 y 1952. Pero además de la frecuencia de su participación, para evaluar la trascendencia de estos y otros músicos en el cine español, hay que considerar la adecuación que alcanzan sus coplas con el estilo de quienes protagonizan estas películas. Imposible olvidar, por ejemplo, a Concha Piquer, una artista que triunfó en los teatros de Estados Unidos durante los años 20, interpretando Ojos verdes en Filigrana (Luis Marquina, 1949).

De cualquier forma, su valor artístico no resta matices ideológicos a las canciones de los musicales folclóricos. Un ejemplo es el pasodoble Capote de grana y oro, interpretado por Juanita Reina en Gloria Mairena (Luis Lucia, 1952). El capote mencionado en el pasodoble es de color grana y no de color rojo debido a la prohibición de la censura: "rojo" era usado por Franco para denominar a su enemigo republicano durante la guerra civil y también después. Las canciones populares andaluzas son el gran atractivo de esta manifestación del musical. Por mucho que la película no tenga gran valor artístico, los temas interpretados por sus cantantes más admirados estimulan al público popular que acude a las salas durante el franquismo para que gaste su escaso dinero en una entrada. 
En definitiva, como consecuencia de la prioridad comercial, la música andaluza suele tener una función básica en una parte considerable de la producción española durante varias décadas. Independientemente de su importancia cuantitativa, los números musicales desempeñan siempre una función central en los argumentos y posibilitan que las situaciones se sucedan las unas a las otras con total fluidez.

La pertenencia de sus protagonistas al negocio del espectáculo favorece la inserción de las canciones en las películas folclóricas. Y sólo unos pocos casos son Torbellino (Luis Marquina, 1941), La Lola se va a los puertos (Juan de Orduña, 1947), El sueño de Andalucía (Luis Lucia, 1950) o iBienvenido Mr. Marshall! (Luis García Berlanga, 1953). En este cine se canta encima de un escenario y para un público. Aunque, como en los musicales de otros países, en estos ejemplos españoles las canciones también subrayan las actitudes de los personajes o su estado psicológico.

Entre los años treinta y los años sesenta, las canciones de estos musicales folclóricos se escuchan casi siempre en la voz de la protagonista femenina. Sólo a partir de los años 50, las estrellas masculinas como Luis Mariano, Antonio Molina o Manolo Escobar van a ser más frecuentes en el primer lugar de los títulos de crédito.

También hay casos en los que los temas musicales incluidos en estas películas son interpretados por parejas, unidas normalmente por sentimientos amorosos. Así ocurre en todas las producciones interpretadas por Luis Mariano, al que habitualmente da la réplica otra estrella famosa, Carmen Sevilla. También hay casos excepcionales de temas interpretados por parejas cómicas. Es el caso de Échale guindas al pavo, al que Imperio Argentina y Miguel Ligero dan un tono intensamente burlón en Morena Clara.

Los números de carácter coral son raros en el cine musical folclórico español y las causas parecen claras: el extraordinario carisma de los personajes protagonistas y la carencia de medios de producción necesarios para la puesta en escena de las secuencias colectivas. Sin embargo, en estas películas también se incluyen algunas canciones interpretadas por grupos amplios de personajes: es el caso del número musical más famoso de iBienvenido Mr. Marshall!, en el que todos los habitantes del pueblo de Villar del Río cantan a coro para ensayar 
el recibimiento que darán a sus supuestos benefactores estadounidenses: "Os recibimos, americanos, con alegría. iOle mi madre, ole mi suegra y ole mi tía!”.

Al contrario de lo que ocurre en el cine musical estadounidense, en el que el baile resulta fundamental para el desarrollo de los argumentos, en esta modalidad española del género, las escenas coreografiadas son escasas y poco relevantes, sobre todo si se las compara con la función central de las canciones en los argumentos.

Hay algunas películas, sin embargo, en las que se incluyen secuencias de este tipo. En Morena Clara hay un número de baile. Se trata de unas sevillanas interpretadas por varios miembros femeninos de la figuración. Con la coreografía se acentúa el ambiente festivo que define la escena, una celebración organizada en la casa familiar del protagonista masculino. Este caso es un reflejo muy pálido de los musicales de Hollywood como Oklahoma! (Fred Zinnemann, 1955) en los que los bailes populares aparecen como un ritual comunitario (Feuer, 1992).

Además del ejemplo anterior, hay otra escena coreografiada con una función narrativa trascendente que debe reseñarse, además, por su carácter onírico. Un rasgo excepcional en un cine folclórico que no suele establecer diferencias entre la realidad y la fantasía a través de los números musicales, como sí ocurre en las películas de Hollywood. Se trata de la secuencia que interpreta Carmen Sevilla junto con un numeroso cuerpo de baile en Un caballero andaluz (Luis Lucia, 1954). En este fragmento, el personaje sueña que se ha convertido en una gran estrella del baile.

La puesta en escena a través de planos muy generales y movimientos largos de la cámara y el decorado surrealista recuerdan, con menos medios, la puesta en escena del último número de Fred Astaire y Cyd Charisse en The band vagon (Vicent Minnelli, 1953).

Aunque el virtuosismo técnico no suele ser frecuente las películas folclóricas, que se producen con poco tiempo y pocos medios, se puede reseñar algún ejemplo en el que la planificación cobra especial relevancia para ensalzar la música y la coreografía. En el número de baile antes citado que se incluye en Morena Clara, tanto la ubicación de la cámara como su angulación dan una 
visión del baile que recuerda, aunque con menos complejidad, a los planos cenitales de los musicales coreografiados por Busby Berkley en Hollywood.

Sin embargo, dejando de lado los ejemplos anteriores, en la mayoría de las canciones interpretadas en estas películas, los elementos de expresión corporal aportados por el vocalista, normalmente la protagonista femenina, suponen un valor añadido. El caso más claro el de Lola Flores, que, absolutamente magnética y personal, siempre añade un valor expresivo excepcional en los números de sus películas.

Pero más allá de sus implicaciones narrativas, la música y el baile pueden considerarse incluso rasgos definitorios de los personajes que aparecen en los musicales folclóricos. Incluso si no tienen que ver con el mundo artístico, sobre todo las mujeres de estas películas se definen a través del cante y el baile. Buenos ejemplos son Gloria (Imperio Argentina) en La hermana San Sulpicio (Florián Rey, 1934) o la hermana Consolación (Lola Flores) en La hermana alegría (Luis Lucia, 1954). Aunque ambas son monjas, lo mismo que en otros personajes femeninos que aparecen en películas del género, su temperamento resuelto y su jovialidad se canalizan a través de la música.

La gran época del musical folclórico termina a principios de los años 6o. $E l$ balcón de la luna (Luis Saslasky, 1962), protagonizada por tres de sus grandes estrellas, Lola Flores, Carmen Sevilla y Paquita Rico, puede considerarse la culminación y el principio del fin.

La novicia rebelde (Luis Lucia, 1971) ya manifiesta el cambio experimentado por esta modalidad española del musical. Se trata de la tercera versión $L a$ hermana San Sulpicio. Se mantienen los personajes la muchacha de clase alta que se mete a monja, Gloria (Rocío Dúrcal) y del doctor Sanjurjo (Guillermo Murray), que esta vez proviene de México. Los arreglos musicales son de Antón García Abril, que les da un aire pop acorde con el estilo de la protagonista. Esta influencia estética se acentúa por los decorados y por los cuerpos de baile que intervienen en los números musicales, interpretados por Rocío Dúrcal y, la gran mayoría, con una función onírica.

El carácter reflexivo de La novicia rebelde es el rasgo que más la diferencia de los musicales folclóricos clásicos. En la primera secuencia, el personaje de Gloria se dirige a cámara para contar que su historia de amor con el médico 
mexicano estaba planeada por el destino, "sin contar con que esta es una coproducción y el galán tenía que venir de América”, según añade el propio personaje. El cuento de hadas se consuma cuando, tras el beso final, Gloria hace un guiño al espectador a través de la cámara. Este gesto también consuma el final la modalidad más española del género musical.

\section{Pena, penita, pena (Miguel Morayta, 1953): cine folclórico también para la exportación}

Esta película es el primero de los nueve musicales folclóricos interpretados por Lola Flores en México entre 1953 y 1964. Todos estos títulos fueron cofinanciados por diferentes empresas mexicanas, como Diana Films o Filmex, y Suevia Films, la productora más importante de España entre los años 50 y finales de los 60.

El objetivo comercial de la empresa propiedad de Cesáreo González quedaba claro: las cantantes folclóricas, las más importantes de las cuales habían firmado contratos en exclusiva con Suevia Films, obtenían grandes éxitos también en los países de Latinoamérica. Por tanto, las películas protagonizados por ellas tendrían allí un numeroso público potencial que permitiría aumentar la rentabilidad. Nada más lógico, para penetrar en estos mercados, que utilizar la modalidad folclórica del musical y la identificación entre lo andaluz y lo español que la define.

Con este planteamiento comienza la producción de Pena, penita, pena, que, en una industria cinematográfica débil como la española, resulta destacable por que su fin es ser comercializada también en el exterior. Para fomentar el interés del público de México y otros países de la zona al que también se pretendía llegar, en el reparto de este musical, Lola Flores comparte protagonismo con una gran estrella de la música mexicana, Luis Aguilar, y otro actor también muy popular, Antonio Badú. El elegido para dirigir la película fue un profesional eficaz, Miguel Morayta, uno de los muchos españoles emigrados tras la Guerra Civil que trabaja en México.

La película narra cómo Carmen Heredia (Lola Flores), una gitana andaluza que vende billetes de lotería, conoce a Carlos (Antonio Badú) y Luis (Luis Aguilar), 
dos hermanos mexicanos sin dinero. Los tres deciden comprar un billete de lotería: si obtuvieran algún dinero, los hermanos podrían regresar a su país y la gitana iría a buscar a su novio torero, Antonio, del que no tiene noticias. El billete resulta premiado, pero, al llegar a México, Carmela es rechazada por Antonio. La gitana empieza a actuar en un café con gran éxito. Aunque se produce un conflicto cuando los dos mexicanos se enamoran de ella, Carlos acepta la situación y Carmen y Luis acaban felizmente unidos.

Esta película se plantea en función de la figura de Lola Flores. Su personaje está definido básicamente por su procedencia andaluza, como ocurre con las protagonistas de otros musicales folclóricos de esta gran época del género. A este respecto, el marcado acento y la caracterización son sus rasgos más característicos. La estética de esta protagonista está claramente identificada con la imagen femenina de lo andaluz, con tejidos estampados, faldas de volantes y flores en el pelo, cuando vende lotería en Madrid o cuando actúa en un escenario. Pero, ya en México, su definición externa sigue siendo inconfundible en este sentido aunque aparezca más suavizada.

Pero, además de su por su españolidad de raíz andaluza, este personaje encarnado por Lola Flores se singulariza por sus contrastes. Por una parte, Carmela se aferra a unos rígidos valores morales en su relación con los hombres. Sin embargo, paradójicamente, en el cine español del franquismo es difícil encontrar un personaje femenino que se comporte con mayor libertad. Ella decide viajar a México con dos hombres a los que apenas conoce, ella decide abandonar a su novio. Y es ella también la que elige con cuál de los dos hermanos quiere mantener una relación amorosa. La fuerza que define a las cantantes folclóricas en el franquismo (Woods, 2004), y que tan bien se corresponde con la personalidad de Lola Flores, se concreta en el personaje de Carmen en Pena, penita, pena.

De forma similar a otros ejemplos del cine folclórico, la música y el baile identifican de manera básica a la protagonista principal de esta película. Ya antes de convertirse en una artista profesional, Carmela afirma que ella sabe cantar y bailar como todas las muchachas de su tierra. Resulta destacable esta réplica de la protagonista: la conclusión es que, si es andaluza, cualquier mujer canta y baila. 
Los números musicales son la mejor muestra de cómo la puesta en escena de esta película se concibe con la protagonista como eje. El más significativo de todos ellos es el fragmento en el que Lola interpreta una versión de "Muerto de amor", un poema de Rafael de León, y la copla que da título a la película. Por una parte, hay que destacar la inclusión del recitado, un elemento atípico, al que Lola Flores imprime gran intensidad dramática. Rodado probablemente con dos cámaras, en este número se alternan planos generales en ángulo contrapicado, que engrandecen la figura de la protagonista al retratarla desde abajo, y planos más cercano que recogen sus momentos de mayor expresividad.

Además, esta última interpretación musical culmina la tendencia seguida durante toda la película: el director opta por mantener la cámara quieta. La manera de imprimir mayor dinamismo en la puesta en escena es fragmentar las canciones y bailes incluidos en una cantidad elevada de planos. Además, suelen ser planos de corta duración que sólo se prolongan más cuando se trata de algún momento especialmente intenso en las interpretaciones de Lola Flores.

Como en el ejemplo anterior, que se inserta en la acción cuando Carmela se encuentra desesperada por no haber encontrado a Luis, los números musicales de Lola Flores están concebidos para expresar los estados sicológicos de su personaje. Otra muestra de ello es el momento en el que la protagonista se venga del novio que la había abandonado cantándole desde el escenario del café. En un principio, Carmen no quiere actuar, pero luego canta una bulería, compuesta por Quintero, León y Quiroga, como la mayor parte de las canciones de esta película.

La letra parece celebrar las virtudes del torero, pero, cuando Antonio se muestra más satisfecho, la cantante se burla de él. Se trata, pues, de un número que se justifica por la dedicación profesional de la protagonista, pero que tiene como fin esencial expresar el rechazo de Carmen por el que fue su novio. La importancia de la canción para solucionar el conflicto entre los dos personajes se acentúa por la continua inclusión de primeros planos de Antonio, en los que se ve cómo cambia su gesto a la sorpresa ofendida. Al final, se escuchan en out las risas del público que aplaude. Además, para propiciar la complicidad de los espectadores a los que se destina, entre las canciones de la película se incluye la ranchera Tú, sólo tú. Primero es el personaje de Luis el que entona un fragmento con los instrumentistas de un 
mariachi. Luego, acompañándose de una guitarra, Carmen canta otra parte adaptada al estilo flamenco. Y, finalmente, los dos interpretan a dúo varias estrofas más, de nuevo a la manera convencional.

Además de ésta canción, los dos artistas mexicanos son protagonistas de tres números musicales más de los doce que se incluyen en Pena, penita, pena. De todas estas intervenciones, sólo la ranchera El sinaloense, interpretada por Luis Aguilar, carece de funcionalidad narrativa. En este número, el cantante está acompañado por un grupo de mariachis que toca sus instrumentos. Se trata de la tendencia general en Pena, penita, pena, en la que, con la excepción de dos números, la música es diegética.

Como en todo el musical folclórico español, también en esta película el baile tiene una función menor. Lola Flores baila en todas sus canciones, pero las interpretaciones coreografiadas sólo constituyen el centro de tres de los números. En dos de ellos, aparece una pareja, Carmen Flores y Angelillo. Ambos interpretan dos bailes flamencos acompañados de un guitarrista, que se incluyen en la película para acentuar la ambientación del café dónde actúa Carmen. La protagonista del tercero de los bailes es la propia Lola Flores, que, como se aprecia en un plano de conjunto lateral del escenario y de las mesas dónde están sentados los clientes, realiza parte de su interpretación de frente al personaje de Luis Aguilar.

Este ejemplo pone de relevancia el carácter que adquiere la presencia de quien contempla los números musicales en esta narración. Puede ocurrir que, como en el caso anterior, ese espectador sea alguno de los protagonistas, lo que tiene mucho que ver con la importancia de las canciones como medios para la resolución del argumento. Como ejemplo, además de las "Bulerías de Antonio Torres”, también se puede citar la interpretación que hace Lola Flores del pasodoble España mía. En muchos de los planos en los que aparece la artista encima del escenario, la cámara se sitúa en el mismo lado en el que, teóricamente, está situado el personaje de Carlos, que ha entrado en el café casualmente y está mirando actuar a Carmen, a la que había buscado desesperadamente por las calles de la ciudad.

Pero es más frecuente que la planificación de las secuencias musicales se plantee en función de un grupo numeroso de espectadores, como quienes ocupan las 
mesas del bar de Madrid en las primeras secuencias, o quienes asisten al "Café Cantante España Cañí”. En este caso, son abundantes los planos de conjunto en los que la actuación que se desarrolla en el escenario se sitúa en el contexto del local. Se trata de una manera de contextualizar la acción pero que diluye la identificación del espectador de la película con el público de ficción que está contemplando la interpretación del número musical. Un proceso que caracteriza el musical de backstage realizado en Hollywood (Feuer, 1992).

Como ocurre en Pena, penita pena, los guiones de los musicales folclóricos narran historias en las que los protagonistas cambian su posición social. Además, las estrellas de este cine contradicen el orden franquista: se trata de mujeres trabajadoras y con éxito. $\mathrm{Y}$ todo esto en un país sometido a una rígida dictadura y dónde la posición que ocupa la mujer es secundaria... En definitiva, a través de la modalidad más española del musical, quienes acuden a las salas cinematográficas viven una utopía. Una sensación que, de una manera u otra, han motivado las películas de este género en los públicos de todos los países.

\section{Referencias bibliográficas}

BLANCO MALLADA, L. (2004): Cine musical español 196o-1965, Aula abierta, 8.

BLANCO MALLADA, L. (2004b): Cine musical español. $2^{a}$ parte (1965-1970), Aula abierta, 9.

BLANCO MALLADA, L. (2006): Cine musical español 1975-198o, Aula abierta, 14.

CASTRO DE PAZ, J. L y CERDÁN, J. (Coords.) (2005): Suevia Films- Cesáreo González, 30 años de cine español. Santiago de Compostela, Xunta de Galicia.

COMAS, A. (2004): El star system del cine español de posguerra, 1939-1945. Madrid, T\&B Ediciones.

FERNÁNDEZ HEREDERO, C. (1993): Las huellas del tiempo. Cine español, 1951-1961. Valencia, Ediciones de la Filmoteca.

FEUER, J. (1992): El musical de Hollywood. Madrid, Verdoux.

MONTERDE, J. E. (1995): “Continuismo y disidencia (1951-1962). En GUBERN, R. y otros, Historia del cine español. Madrid, Cátedra.

PÉREZ PERUCHA, J. (ed.) (1997): Antología crítica del cine español. Madrid, Cátedra / Filmoteca Española.

WOODS, E. (2004): "From rags to riches: the ideology of stardom in folkloric musical comedy films of the late 1930 s and 1940s". En LAZARO REBOLL, A. y WILLIS, A. (Eds.), Spanish popular cinema. Manchester, Manchester University Press. 


\section{Filmografía}

Embrujo (Carlos Serrano de Osma, 1947)

iBienvenido Mr. Marshall! (Luis García Berlanga, 1953)

Un caballero andaluz (Luis Lucia, 1954)

El pequeño ruiseñor (Antonio del Amo, 1956)

El último cuplé (Juan de Orduña, 1957)

Un rayo de luz (Luis Lucia, 1960)

El balcón de la luna (Luis Saslasky, 1962)

Al ponerse el sol (Mario Camus, 1967)

Los chicos con las chicas (Javier Aguirre, 1967)

La novicia rebelde (Luis Lucia, 1971)

¿Dónde estará mi niño? (Luis María Delgado, 1980)

Bodas de sangre (Carlos Saura, 1981)

Las cosas del querer (Jaime Chavarri, 1989)

Yo soy esa (Luis Sanz, 1990)

Flamenco (Carlos Saura, 1995)

La niña de tus ojos (Fernando Trueba, 1998)

El otro lado de la cama (Emilio Martínez Lázaro, 2002)

Salomé (Carlos Saura, 2002)

Los dos lados de la cama (Emilio Martínez Lázaro, 2005)

¿Por qué se frotan las patitas? (Álvaro Bejines, 2006) 